\title{
SOBRE LA RELACIÓN ENTRE INDIVIDUALIDAD Y COLECTIVIDAD. NOTAS A EL HECHICERO DE LA TRIBU. MARIO VARGAS LLOSA Y EL LIBERALISMO EN AMÉRICA LATINA DE ATILIO BORÓN*
}

\author{
CAROLINA BRUNA CASTRO**
}

$\mathrm{E}$ Libro de Atilio Borón (2019) es un ajuste de cuentas con Vargas Llosa, quien declara haber dado un giro desde el marxismo/comunismo al liberalismo. Este arreglo de cuentas viene motivado por una fuerte declaración de Vargas Llosa (2018) en su libro La llamada de la tribu. En líneas generales, en este libro se arguye la necesidad de cuestionar los valores colectivos como un tipo de relación que maneja y domina al individuo, tal como sería el tipo de vínculo que es característico de la tribu ${ }^{1}$. Para Vargas Llosa, el individuo no debe vender sus fines, sueños o propósitos a un colectivo, aunque se sienta parte de él. En este contexto se debe leer la metáfora de Vargas Llosa, el concepto de "tribu", como el reemplazo del concepto de "comunidad", pero de una manera despectiva, haciendo eco de la distinción entre "sociedad" y "comunidad" hecha por Ferdinand Tönnies (1979). Tal como lo distinguió el sociólogo alemán, sociedad se refiere a un grupo humano que tiene por base el individuo para establecer relaciones abiertas, mientras que una comunidad es un tipo de vínculo en el que lo medular es la sangre, la cultura y creencia común, también el apego afectivo a un valor.

* Resultado parcial del proyecto Fondecyt 11160037. Esta nota tiene por origen una presentación oral del libro de Borón en la Facultad de Derecho de la Universidad de Chile el día 6 de agosto de 2019. Agradezco al Centro de estudiantes por invitarme a presentar el libro y la disposición de diálogo de Atilio Borón durante dicha presentación. Agradezco a Natalia Morales y Rodrigo Fuenzalida por los comentarios.

${ }^{* *}$ Dra. en Filosofía. Profesora asistente Facultad de Derecho, Universidad de Chile, Santiago, Chile. Correo electrónico: cbruna@derecho.uchile.cl

${ }^{1}$ Asumo que esto puede ser leído de esta manera, pues en la presentación del libro La llamada de la tribu en la Universidad Diego Portales en Santiago de Chile, el rector de esa institución, Carlos Peña, interpreta el libro en estos términos y Vargas Llosa parece asentir. Se puede ver el video en https://youtu. be/euIhNp1mIT4 (consultado 8 de agosto 2019, publicado en el canal UDP 4 de mayo 2018). 
Para Vargas Llosa, la tensión entre individuo y comunidad sin el liberalismo no tiene solución, pues sin este no se puede salir de la tribu. La tribu debe ser caracterizada como una agrupación con el tipo de ligamen de comunidad, la que se ha asociado en general a lo que fue el proyecto del nacionalsocialismo o, lo que intentaron hacer las dictaduras latinoamericanas (Borón insiste con la reiteración de ejemplos dada por el premio Nobel, quien refiere constantemente a Fidel Castro, Augusto Pinochet, entre otros).

Siguiendo este tenor, Vargas Llosa en la presentación de su libro que realizó en mayo de 2018 en Santiago de Chile, ante la pregunta de Carlos Peña por el movimiento feminista, respondió declarándose defensor del feminismo, pero solo el liberal, al tiempo que cuestionó otros tipos de feminismos. Esto es, ocupó la problemática de la tribu para hablar de feminismos, y podríamos decir que distinguió entre "feminismos cerrados" y liberales. Esta distinción lo lleva a cuestionar ciertos discursos feministas que, para él, se manifiestan como discursos cerrados que no defienden la libertad individual, ni la profesión del escritor, este es un punto sensible para Vargas Llosa, ya que insiste en que la falta de libertad individual de aquellos feminismos podría incluir propuestas respecto de libros que deben o no ser leídos. Esta referencia está motivada por la pregunta de la escritora Laura Freixas sobre qué hacer con el libro Lolita de Nabokov, si leerlo o no. Aunque para Freixas la respuesta no era un rotundo no, para el escritor peruano parecía una inquisición sobre la obra literaria, lo que en el contexto de $\mathrm{La}$ llamada de la tribu repercute como la ausencia de defensa de los valores propios y singulares de las disciplinas, ya que estos quedan subordinados a proyectos ideológicos ${ }^{2}$.

En esa misma intervención declara que Sartre seguramente llegará al olvido, pues no logró ser propiamente un intelectual comprometido, sino que terminó, por un lado, escribiendo en un lenguaje intrincado y difícil y, por otro, excluyendo del ejercicio literario a ciertos escritores, como, por ejemplo, cuando declaró que a los poetas o escritores sudafricanos les toca primero pelear por sus derechos y luego hacer propiamente literatura. Vargas Llosa insiste en que en estas dos opiniones hay una contradicción y un gesto que excluye a ciertos lugares y personas de la literatura, lo que va en contra de la libertad individual.

\footnotetext{
${ }^{2}$ Dicho comentario tuvo respuesta pública de María Isabel Peña en el diario The Clinic. Además, en este mismo comentario se indica la polémica con Freixas. Ver Peña, M.I. (2018).
} 
En El hechicero de la tribu Atilio Borón pretende revisar cada tema, autor por autor liberal de los que Vargas Llosa dice haber sido influenciado en su libro La llamada de la tribu. Entre estos autores liberales que motivan al Nobel quiero destacar a I. Berlín, J. Ortega y Gasset, entre otros. Borón declara que Vargas Llosa habla de filósofos como si fuera un especialista; sin embargo, es un mero difundidor de conocimiento, por lo que no puede hacerse cargo del problema en profundidad. Si bien no es mi interés detenerme en cada uno de los autores tratados por Vargas Llosa, concuerdo con que no hay un análisis exhaustivo de ellos. Atendiendo a lo anterior, me detendré en algunos aspectos relevantes que permiten interpelar a Vargas Llosa y también a Borón.

El título de Borón ya nos indica un juego interesante. Si la tribu es la comunidad cerrada y asociamos la metáfora del hechicero con la dominación carismática de Max Weber (2012), se da una paradoja; esta es, Vargas Llosa nos cuenta sobre aquellos autores que le hicieron preferir una sociedad abierta como la liberal, sin dominación conforme a valores, pero él a través de su libro actúa como un ser dotado de carisma que, con la pluma justifica y domina a su público conduciéndole hacia la creencia en los valores liberales. Así, podríamos decir que el colectivo "la tribu" -también puede ser dominada por un hechicero, un encantador de almas que hablando bonito hace entrar en su discurso aquello que le sirve para pavimentar un camino hacia un tipo determinado de sociedad.

Paradójicamente un hechicero puede hacer con los individuos lo mismo que hace una comunidad cerrada: imponer un valor, pero de manera hipnótica, sin la perspectiva crítica que debe mantener el intelectual. En este caso, el hechicero nos lleva hacia valores globales que van borrando las determinaciones locales de los pueblos. La figura del hechicero en algún punto difiere y en otro coincide con la del intelectual comprometido, porque un intelectual podría hacer pensar sobre la realidad del mundo, invitar a la crítica e invitar a los integrantes de la tribu a pensar por sí mismos. Pero en otro nivel el intelectual puede manejar al grupo humano e instaurar una idea de lo que debe ser el sentido común.

De allí que la metáfora descrita antes nos invite a pensar qué es un intelectual, el cual para el mundo académico no debería ser un hechicero. Borón trae la definición de Gramsci de intelectual: “(...) ¿qué es un intelectual? Lo que lo distingue como una categoría sociopolítica especial no es su permanente actividad en el terreno de las ideas sino la función que cumple en el ejercicio de la dominación política" (2019, p. 137). Dentro de esto, siguiendo a Gramsci (2017), podríamos hablar del intelectual académico y 
del orgánico, considerando al orgánico como un encargado de mantener la ideología, y en tal medida, es aquel que se roza con el hechicero. En cambio, el intelectual académico trata de mantenerse en el terreno del debate de ideas y a veces resistiendo al contexto. Así, Vargas Llosa es un intelectual del liberalismo, orgánico, encargado, desde abajo con un lenguaje fácil y estilizado, de mantener la ideología del capital. (Respecto de esto ver Gramsci, 2017, pp. 269-333).

Por lo anterior, para Borón, Vargas Llosa cumple el rol de un intelectual orgánico que mueve la muchedumbre, genera consenso y seguramente cierta coerción desde la opinión pública de la masa, que sigue el sistema sin cuestionarlo. Me parece que Borón tiene razón sobre Vargas Llosa. La biografía intelectual que utiliza para transitar entre distintos pensadores con el propósito de defender el liberalismo nos deja una caricatura sin contraste de lo que cada uno pensó, razón por la cual, cada uno de los filósofos es utilizado para mostrar ciertos rasgos que sostienen que la idea de liberalismo es la única forma de relacionarnos socialmente, sin contrastar ni distinguir aspectos económicos, sociales o teóricos. Así, paradójicamente, Vargas Llosa se convierte en lo que crítica.

Que el trabajo respecto de los autores liberales sea superficial no es problema para Vargas Llosa mismo. De hecho, en el lanzamiento realizado en Santiago en 2018 indicó que no pretendía más que abandonar a esos filósofos que escribían para una minoría letrada -como Sartre-, en busca de aquellos que, defendiendo la democracia, acercaban la filosofía a la gente común, y que en esa búsqueda se encontró con que estos son justamente quienes defienden ideas del liberalismo. Así, el Nobel no pretende hacer un tratado filosófico, sino que, al igual que quienes admira, escribir para las masas, en palabras sencillas.

Pese a que coincido con los aspectos relevados por Borón, quiero reconocer algo del testimonio de Vargas Llosa que me permite, a su vez, interpelar a Atilio Borón. El escritor peruano declara que una de las razones que lo llevó a alejarse del marxismo es que hay temas tabú asociados al liberalismo que la izquierda y las posiciones colectivistas no han querido discutir. Dicho de otro modo, hay conceptos o temas intocables para la izquierda que probablemente contribuirían a hacer una autocrítica. Por ejemplo, ¿qué pasa con la idea de libertad?, ¿o con la idea de individuo? ¿Son ideas que podemos reclamar como necesarias para poder levantar el concepto de un sujeto latinoamericano?, ¿son ideas centrales para hablar de pluralidad de modos de vida? 
Jorge Millas, filósofo chileno que defendió siempre la democracia, que se mantuvo crítico en abierta diferencia y molestia respecto del liberalismo de Hayek y de la dictadura, tiene en Ortega y Gasset un faro que le permite hablar de la individualidad; de una individualidad que se puede levantar contra la masa y contra el sentido común mediocre, en cuanto estatus quo de lo que la gente "como uno" piensa (Millas, 2009). Podríamos decir que la idea de individualidad, para el chileno, se puede entender equivalente a la de singularidad, a la idea de que tenemos una historia y ciertas características situadas que nos definen en nuestra individualidad. Su propuesta está lejos de defender al individuo egoísta o aislado, sin una relación con su comunidad.

Lo mismo pasa con la idea de libertad. Millas la defiende como un valor que el derecho debería resguardar, pero no la comprende en los términos de mercado. El filósofo chileno le dirá a Hayek que su idea de libertad está equivocada, que libertad no puede ser entendida como una mera libertad negativa (usando temas afines a Berlín). En ese contexto, Millas (1999) explica que Hayek trata la libertad como una capacidad, como la mera elección entre las posibilidades que el sistema económico entrega al ser humano. Esto no es, ni puede ser así, Millas explica que Hayek confunde el que alguien sea o no dueño de sí mismo y pueda o no escoger su propio camino, con las posibilidades entre las que debe escoger (pues no tiene otras por su condición social), sean estas muchas o pocas. Estos dos aspectos para el filósofo chileno son dos cuestiones completamente distintas (pp. 192-195). Para Millas, la libertad cumple un rol de norma fundante y su definición incluye sus aspectos negativo y positivo (en la tipología de Berlín), nos define como seres humanos y nos iguala en forma. Siguiendo a Millas, si el Estado quiere resguardar la libertad, debe reconocer los tipos de individualidades que se muestran en la sociedad; por lo tanto, las y los intelectuales deberían hacer el ejercicio crítico que nos invite a pensar y también a actuar por su reconocimiento.

Si hacemos eco de lo pensando por Millas, entre otros que no han sido mencionados en esta nota, me pregunto, ¿tenemos que quedarnos con la idea de individuo egoísta cuando hablamos de libertad?, ¿debemos entregar conceptos e ideas que nos pueden ayudar a pensar, re-pensar y proponer nuevas formas de vida común a propuesta de defensa de la individualidad egoísta?

Ante esto, debemos ser conscientes sobre el modo en que las ideas modernas nos influencian, cómo las variamos, y con ello, encarar que muchos 
de nuestros conceptos políticos provienen de la tradición que cuestionamos. Por ejemplo, la democracia es portadora -o mejor dicho- es definida en sí misma por múltiples paradojas, que provienen de su relación con el liberalismo. La democracia tal como la conocemos se la debemos -con todas sus virtudes y defectos (quizá son más estos últimos)- al pensamiento liberal moderno. Borón menciona a Locke, Kant, Constant, entre otros -sumo a Hobbes-, como los primeros liberales y declara que ninguno defendió la democracia, pero es necesario aclarar que, sin el aporte de ellos, la democracia no sería tal cual como la conocemos (Borón, 2019, pp.175-185). Los modernos antes mencionados reconocieron que su pensamiento político era válido para justificar cualquier modo de gobierno, incluso la democracia, no obstante, ellos preferían otro.

Esta democracia tal cual la conocemos hoy está en crisis, fundamentalmente porque la representación política decepcionó al no poder dar cuenta de lo colectivo. El voto no implica participación, y las personas nos sentimos presas del sistema y nos aislamos en las necesidades del diario vivir. Para entender esta crisis podemos tomar la crítica al liberalismo de alguien tan conservador como Schmitt y le podríamos encontrar razón. La democracia -paradójicamente al igual que el estado autoritario- finalmente es una herencia de la lógica hobbesiana y del contrato, en el marco de la cual se justifica la existencia del Estado, con la trasferencia de derechos individuales a una persona ficticia que nos representa. Eso es lo que hacemos cada vez que votamos por alguien que llega al parlamento o a la presidencia. Además, esa misma lógica hobbesiana acaba con la comunidad cerrada, anclada en la creencia en una religión que mantuvo el medioevo. Esa lógica nos abre a la alteridad y, a la vez, nos aísla. Así, pese a la intención de quebrar la unidad cerrada del tipo de comunidad religiosa, esta lógica nos lleva a un tipo de vida polarizado, individualista, centrado en el placer y el deseo individual de obtener bienes y llevar una vida confortable ${ }^{3}$. En ese contexto, la colectividad pierde peso, más aun, tristemente, lo colectivo pasa a ser una mera relación clientelar en la que pensar en los roles públicos, la solidaridad y el compromiso social termina siendo secundario

\footnotetext{
${ }^{3}$ Para entender los problemas de la lógica de la representación moderna y el poder, lo que expreso aquí toma en consideración el trabajo de Giuseppe Duso (2010). Por mi parte, lo he planteado en otros lugares para mostrar lo paradojal del pensamiento de Hobbes que nos muestra dos aristas relevantes de nuestra formación colectiva, la necesidad de reconocer la alteridad, el centro en el individuo y el lado más explotado, la centralidad de la autoridad que lleva al autoritarismo (Bruna Castro, 2019). Estas ideas no niegan que, en la propuesta contractualista, en Hobbes mismo esté el origen común del Estado democrático y el autoritario.
} 
ante la comodidad de la vida individual, en donde es más importante tener trabajo y un sueldo que permita consumir ${ }^{4}$.

Ante esta lógica individualista, es muy difícil pensar lo colectivo para nosotras. Así como el feminismo destaca una lógica patriarcal, debemos pensar también en una lógica más amplia que impera en nuestra sociedad, esta es, la individualista. Así las cosas, quedan preguntas abiertas más allá de la crítica a Vargas Llosa. Considerando que la ilusión y creencia en las instituciones políticas está en crisis, incluida la vida de los partidos políticos, ¿ cómo formamos una comunidad/sociedad, o mejor, colectividad, que se haga cargo de la idea de individualidad de Millas -no de individuo atomizado- a la vez que de lo colectivo? ¿cómo re-encantamos, o mostramos que los valores de lo colectivo movilizan y hacen un mundo mejor? La cosa parece no ser tan fácil y quedan estas preguntas que invitan a buscar soluciones para motivar a la participación, para creer nuevamente en los partidos políticos y en las instituciones políticas, o a lo menos en otras formas de manifestar lo colectivo. Nos quedamos entonces con la siguiente pregunta: ¿cuál es la tarea de las personas que nos interesamos en lo político y en lo colectivo cuando somos filósofas, filósofos, teóricas, teóricos?

\section{REFERENCIAS}

Borón, A. (2019). El Hechicero de la tribu. Mario Vargas Llosa y el liberalismo en América Latina. Ciudad de México, México: Akal.

Bruna Castro, C. (2019). ¿Teología política? Una propuesta a propósito de $L a$ forma del derecho de Fernando Atria. Revista de Estudios de la Justicia, 29, 39-58.

Duso, G. (2010). El poder y la génesis de los conceptos políticos modernos en S. Chignola y G. Duso (eds.), Historia de los conceptos (pp. 197-233). Madrid, España: Biblioteca Nueva.

Gramsci, A. (2017). Sentido común, intelectuales y cultura democrática. En C. Rendueles (Ed.), Gramsci. Escritos antología (pp. 269-333). Madrid, España: Alianza.

\footnotetext{
${ }^{4}$ Esta lógica de pensamiento llega a ser tan propia de nuestro tiempo que entra por formas intuitivas de imponer un modo corrector de ver la vida. Por poner un ejemplo, refiero a Meet King Joe, una caricatura de 1949 en la que la Metro Goldwyn Mayer presentaba al rey de los trabajadores; un ser humano promedio que tenía una buena vida gracias al capital, y que gracias a los avances del capital había logrado alivianar su trabajo y subir su sueldo; con ello, la comodidad y su capacidad adquisitiva se había incrementado al punto de sentirse como un rey. La caricatura insiste en que esto es solo posible en el capitalismo que es sostén de la vida de los Estados Unidos y por eso no hay rey de los trabajadores en otros lugares.
} 
Millas, J. (1999). La concepción de libertad-poder de Friederich von Hayek. Araucaria, año 1, (2), 192-206.

Millas, J. (2009). Idea de la individualidad. Santiago, Chile: Ediciones Universidad Diego Portales.

Peña, M. I. (2018, mayo 19). El viejo patriarcado se disfraza de buen feminista. The Clinic. Recuperado de https:/www.theclinic.cl/2018/05/19/columnamaria-isabel-pena-viejo-patriarcado-se-disfraza-buen-feminista/

Tönnies, F. (1979). Comunidad y asociación. Barcelona, España: Península.

Vargas Llosa, M. (2018). La llamada de la tribu. Madrid, España: Alfaguara.

Weber, M. (2012). El político y el científico. Madrid, España: Alianza.

Filmografía

Presentación de La llamada de la tribu de Vargas Llosa en la Universidad Diego Portales, mayo 2018, Santiago, Chile. Disponible en https://youtu.be/euIhNp1mIT4 (consultado 8 de agosto 2019).

Meet King Joe (1949). Producciones John Sutherland, American Studies Institute at Harding College Animation, distribuida por Metro-Goldwyn-Mayer. 